\title{
PENDEKATAN PERSEPSI DAN KOGNISI DALAM ANALISIS IDENTITAS KOTA, STUDI KASUS KAWASAN PUSAT KOTA MALANG
}

\author{
Tonny Suhartono, Philipus Agus Sukandar dan Imam Santoso \\ Program Studi Arsitektur, Fakultas Teknik, Universitas Merdeka Malang
}

*tonny.suhartono@unmer.ac.id, philipus.agus@unmer.ac.id, imam.santoso@unmer.ac.id

\begin{abstract}
ABSTRAK
Arsitektur Kota dan identitasnya yang bukan sekedar gambar (wujud fisik-visual) dari kota yang bisa dilihat saja, melainkan juga sebagai suatu konstruksi. Konstruksi yang terbentuk sepanjang waktu melalui proses yang panjang, akibat interaksi antara manusia, budaya, sosial dan factor-faktor alamiah. Permasalahan (issue) tentang kota banyak dilontarkan berbagai pihak; ada yang menyatakan pembentukan ruang kota harus selalu berkaitan dengan aspek fisik dan faktor-faktor yang melatarbelakanginya. Para perencana dan perancang (arsitektur) kota ditantang untuk menciptakan lingkungan binaan kolektif yang berarti bagi pertumbuhan serta keberlanjutan kehidupan manusia. Saat ini terjadi kecenderungan penurunan kualitas arsitektur tata ruang dan karakter pada pusat kota, yang disebabkan oleh pendekatan yang lebih menekankan segi fungsional dan pemenuhan kepentingan perekonomian semata. Seringkali hasil- hasil dari para perencana-perancang itu menjadi buruk dalam wujud maupun denah (tata ruang) bagi penggunaan untuk aktivitas kehidupan secara publik. Dalam rangka menjembatani permasalahan tersebut kegiatan persepsi dan kognisi lingkungan kota dapat digunakan untuk menganalisa bentuk ruang dan kualitas sebuah kota. Dalam kegiatan perancangan kota yang bersifat visual persepsual tentu saja kegiatan kognisi sangat bermanfaat. Secara umum kognisi adalah kegiatan atau proses memperoleh pengetahuan termasuk kesadaran, perasaan dsb, atau usaha menggali sesuatu melalui pengalaman sendiri. Termasuk kegiatan kognisi antara lain proses pengenalan, penafsiran lingkungan dalam rangka memperoleh hasil pengetahuan. Tulisan ini mencoba menyampaikan metode mengenali ruang dan karakter kota dengan studi kasus Kawasan Pusat Kota Malang dan menggunakan kriteria kinerja dalam teori Perancangan Kota Kevin Lynch..
\end{abstract}

Keywords: Identitas dan karakter arsitektur kota, kriteria kinerja Lynch, persepsi dan kognisi arsitektur,

\begin{abstract}
Architecture of the City and its identity is not just a picture (physical-visual form) of the city that can be seen only, but also as a construction. Construction is formed all the time through a long process, due to interactions between humans, culture, social and natural factors. Many Issues about the city raised various parties; some say the formation of urban space must always be related to the physical aspects and the
\end{abstract}


underlying factors. Urban planners and designers are challenged to create a collective built environment that is meaningful for the growth and sustainability of human life. Currently there is a tendency to decrease the quality of spatial architecture and character in the city center, which is caused by an approach that emphasizes the functional aspects and the fulfillment of economic interests only. Often the results of the planners are bad in form and layout for use in public life activities. In order to bridge these problems, the perception and cognition activities of the city environment can be used to analyze the shape and quality of a city. In city planning activities that are visual perceptual, of course cognitive activities are very useful. In general cognition is an activity or process of gaining knowledge including awareness, feelings, etc., or an effort to explore something through one's own experience. Which includes cognitive activities including the process of recognition, interpretation of the environment in order to obtain the results of knowledge. This paper tries to convey the method of recognizing the space and character of the city with a case study, the Center Area of Malang City and using performance criteria in Kevin Lynch's City Design theory.

Keywords: Identity and character of city architecture, Lynch's performance criteria, architectural perception and cognition, 


\section{PENDAHULUAN}

Identitas kota pada hakekatnya merupakan jejak peradaban yang ditampilkan sepanjang sejarah kotanya. Sebagai perwujudan proses panjang, identitas tak bisa difabrikasikan pada suatu saat saja, seperti "instant culture" atau budaya dadakan. Sebagai akibatnya wajah kota justru akan menjadi palsu, sarat dengan manipulasi. Permasalahan (issue) tentang kota banyak dilontarkan berbagai pihak; antara lain menyatakan bahwa pembentukan ruang kota harus selalu berkaitan dengan aspek fisik dan faktor-faktor yang melatarbelakanginya. Hingga saat ini para perencana dan perancang (arsitektur) kota menemui berbagai tantangan dalam menciptakan lingkungan binaan kolektif yang berarti bagi pertumbuhan serta keberlanjutan kehidupan manusia. Kecenderungan yang terjadi justru penurunan kualitas arsitektur tata ruang dan karakter pada pusat kota, yang disebabkan oleh pendekatan yang lebih menekankan segi fungsional dan pemenuhan kepentingan perekonomian semata.

Hasil-hasil perencanaan dan perancangan bahkan menjadi buruk dalam wujud maupun tata ruang bagi aktivitas kehidupan publik. Upaya pembangunan ulang dari segi fisik yang sangat deterministik membuat lingkungan kota cenderung semakin kacau dan menyebabkan terjadinya pergeseran-pergeseran yang mengakibatkan citra kota memudar. Agar lingkungan kota tidak terbentuk akibat kekuatan ekonomi sematamata, maka diperlukan suatu tindakan korektif yang bertujuan menjaga keindahan dan keserasian lingkungan.

\section{KAJIAN PUSTAKA}

\section{Kota adalah arsitektur.}

Arsitektur kota yang membentuk wujud/wajah kota merupakan kegiatan makro yang bersifat "proses oriented", dan berbentuk dua dimensional. Untuk memperoleh arsitektur kota yang baik maka dibutuhkan metode dan instrumen untuk menerjemahkan keputusan/kebijakan kedalam bentuk tiga dimensional, yaitu perancangan kota. Perancangan kota yang baik, dapat dilihat dari tampilan bentuk ruang dan bentuk fisik yang bersifat tangible dan yang bersifat intangible berkaitan dengan kondisi masyarakatnya. Roger Trancik (1986) menyatakan bahwa pemahaman tentang kultur dan karakteristik suatu daerah yang ada dan telah menjadi ciri khas, dapat dipakai sebagai sajian satu bahan pertimbangan dalam menciptakan lingkungan, agar penghuni tidak merasa asing dengan lingkungan tersebut. Sedang C. Norberg Schulz (1980) menyatakan untuk menghindari ketunggal rupaan maka identitas lingkungan dan sense of place suatu daerah harus dipertahankan.

\section{Pendekatan Konseptual Persepsi dan Kognisi sebagai Metode Perancangan Kota}

Secara umum kognisi adalah kegiatan atau proses memperoleh pengetahuan termasuk kesadaran, perasaan dsb, atau usaha menggali sesuatu melalui pengalaman sendiri. Termasuk kegiatan kognisi antara lain proses pengenalan, penafsiran lingkungan dalam rangka memperoleh hasil pengetahuan. Dalam kegiatan perancangan kota yang bersifat visual persepsual tentu saja kegiatan kognisi sangat bermanfaat. Proses kognisi melalui pengamatan sebuah kota dapat dilakukan beberapa pendekatan, bisa dari sejarah, hubungan dari 
kelompok manusia, hubungan saling ketergantungan, dan dimensi konfliknya. Persepsi dan kognisi melalui pengamatan yang cermat dari pola hubungan yang terjadi pada kota tersebut juga terhadap bentuk fisik yang melatar belakanginya serta dimensi-dimensi fungsi yang sifatnya non fisik. dapat memperlihatkan kejelasan dan kekurangan bentukan fisik kota tersebut. Intinya adalah persepsi dan kognisi lingkungan kota dapat digunakan untuk menganalisa bentuk ruang dan kualitas sebuah kota.

Teori Perancangan Kota Kevin Lynch merupakan salah satu dari beberapa teori perancangan kota yang berbasis pada pendekatan persepsi dan kognisi. Teori tersebut memiliki kriteria kinerja yang dapat digunakan untuk menguji dan mengkaji kecocokan atau ketidak cocokan suatu proses perancangan kota. Dengan asumsi awal bahwa pusat kota Malang tidak ada kesesuaian dengan teori perancangan kota, maka digunakan modifikasi "kriteria kinerja" dari teori perancangan kota Kevin Lynch yaitu :

1. Vitalitas yang berkaitan dengan fungsi pemenuhan hajat hidup warga kota.

2. Sense, berhubungan dengan Identitas, Struktur, Congruence, Transparensi, Legibilitas

3. fitness berkaitan dengan pola perilaku

4. Access, berkaitan dengan pola hubungan kawasan

5. dan Control

\section{Identitas Kota}

Identitas merupakan pengenalan bentuk ruang dan kualitas yang paling sederhana, pengertian umum secara sederhana tersebut adalah disebut : “A Sense of Place". Pemahaman tentang nilai dari tempat disini merupakan pemahaman tentang keunikan dari suatu tempat secara khusus, bila dibandingkan dengan tempat lain. Keunikan biasanya merupakan kualitas khusus yang selalu diamati dan dibicarakan oleh para desainer. Identitas ini oleh Schulz (1980) disebut image ; penjabarannya dalam bentuk suatu kesan misterius dari pesona Kota Praha. Schulz menggambarkan Kota Praha seolah perasaan pengunjung bila masuk pada beberapa tempat, akan memberi karakter atau identitas, baik pada kondisi jalan, jembatan, halaman-halaman, tangga rumah dan lain lain. Gambaran tersebut seolah membawa pengunjung pada sebuah "kedalaman” yang tidak berujung. Penjabaran Schulz ini, dipusatkan pada guideline Kota Prague yang berupa menara-menara, puncak-puncak menara dari gereja, bentuk-bentuk jendela, dan tonjolan ujung atap dari rumah-rumah tua. Identitas dapat juga berupa peristiwa-peristiwa; yang oleh Lynch disebut Sense of Occasion. Peristiwa dan tempat akan saling menguatkan satu dengan yang lain, untuk menciptakan suatu keberadaan yang gambling. Pemahaman tentang suatu kejadian, oleh Schulz digambarkan dari fungsi dan makna jembatan Charles ;

Place berbeda dengan space dari tingkat pemaknaannya. Place mengkaitkan arti kontekstual yang diturunkan dari kandungan kultural yang ada. Place dapat menjelaskan tentang tipologi-tipologi yang ada, yang menyangkut sesuatu yang unik, khas, dan memberikan karakter terhadap lingkungan tersebut. Karakter itu bisa diukur dari kondisi material atau hal-hal lain yang tak terukur, seperti budaya. Budaya dan pola kehidupan sosial menjadi karakter karena merupakan suatu sistem yang sudah stabil dan terpola di dalam place, yang dibangun sepanjang sejarah masyarakatnya. 
Dengan demikian untuk memandang makna suatu tempat yang dibentuk oleh "Specific Culture" bisa dari pendekatan latar belakang terjadinya bentukan fisik ruang yang dikaitkan dengan budaya masyarakatnya (baca segi historis), dengan langkah-langkah pengamatan seperti: latar Belakang bentukan fisiknya, latar belakang budaya dan makna yang terjadi antara aktivitas dan fasilitas. Pengamatan tersebut tidak lepas dari faktor skala waktu dan ruang dari perkembangan pandangan masyarakat terhadap lingkungan kota.

\section{Struktur Kota}

Struktur adalah hubungan skala dari tempat yang kecil dengan bagian-bagian tempat lain dalam suatu orientasi yang baik, sehingga dapat memberi arti pada peninjau. Orientasi berhubungan dengan waktu dan ruang, orientasi yang baik akan memudahkan orang untuk mencapainya. Sedang orientasi yang jelek cenderung membuang-buang waktu, dan menyia-nyiakan usaha, khususnya bagi orang-orang asing (non-lokal). Orientasi dapat dibantu melalui: waktu dan jarak (view), nodes, patbs, edges, dan landmark (Lynch, 1981: 134).

Struktur menurut Trancik (1986), digambarkan pada figure-ground dan lingkage theory. Figure Ground Theory, lebih ditekankan pada keterpaduan antara massa dan ruang, yang didasarkan bentukan secara alamiah dalam menuju pada keteraturan pada bagian lingkungan kota. Untuk kekuatan analisisnya guna mendapatkan suatu identitas, dengan tekstur dan masalah bentukan tata ruang secara dua dimensional. Linkage Theory, adalah pendekatan bentuk kota dengan melalui suatu sirkulasi yang dinamis, sehingga mencerminkan suatu hubungan pergerakan yang runtut. Dengan demikian pendekatan ini dapat memberikan banyak arti tersendiri bagi pengamatnya. Pendekatan ini dapat melalui definisi tata ruang dan kualitas dengan beberapa penilaian. Figure Ground dan Linkage Theory, bila dikaitkan dengan makna kinerja sense, termasuk pada elemen struktur, yang mana sebagai gabungan hubungan pada skala dari tempat yang terkecil dengan bagian-bagian tempat lain dalam satu orientasi yang baik, sehingga dapat memberi arti pada pengunjung. Kedua pendekatan tersebut samasama dari definisi tata ruang dan kualitas, dimana oleh Lynch dipertegas melalui nodes, paths, edges, districs dan landmarks.

\section{Congruence}

Identitas dan struktur adalah aspek-aspek bentuk yang memudahkan kita mengenali dan mempola tempat dan waktu, di dalam unsur lokasi/ tempat itu sendiri. Congruence merupakan tingkatan pertama kesesuaian formal dari struktur lingkungan sekitar dengan struktur yang tidak berkaitan dengan ruang atau tempat tersebut, pencapaiannya bisa melalui penilaian terhadap kondisi ruang dan kualitasnya, yakni: (1) Apakah tipologi bangunan sesuai dengan fungsi dan masyarakat sebagai pengguna, (2) Apakah pusat kota membentuk kepadatan yang paling tinggi pada puncak-puncak kegiatan, (3) Apakah irama dari kegiatan yang nyata sesuai dengan irama dari aktivitas sosial?

Congruence merupakan dasar persepsi dari lingkungan sekitar yang penuh arti. Contohnya sebuah tempat parkir yang besar bisa jadi terkesan sangat jelek, tidak memuaskan, dan mengganggu kenyamanan. Tempat ini mempunyai arti lebih pada halaman penyimpanan mobil dengan mobil-mobil yang berjejal juga dengan begitu banyaknya ruang-ruang yang kosong. Tetapi bila kita melihat tempat parkir disebelah rumah dengan 
gelaran mobil keluarga, maka bisa jadi mengesankan sebuah kepribadian pemilik rumah bagi para tetangga yang mengetahuinya.

Congruence oleh Schulz digambarkan dalam bentuk character penjabarannya diambil dari sifat Kota Praha yang tidak dapat dipahami tanpa melibatkan lingkungan alaminya. Dengan "lingkungan alami", menurut Schulz tidak hanya dapat mengingat tempat di Kota Praha, tetapi juga Bohemia sebagai di Kota Praha, sebagai satu kesatuan dari wilayah Kota Praha (Schulz, 1980 : 97).

\section{Transparensi}

Menggunakan "kepekaan" pada umumnya yaitu “kemampuan untuk ditangkap oleh indera." Disini yang dimaksud kepekaaan secara langsung dalam mengamati operasi dari berbagai ragam fungsi teknis, seperti : aktivitas-aktivitas, dan proses-proses sosial dan alami yang terjadi di dalam sebuah lingkungan perkotaan. Beberapa dari proses-proses ini adalah penting, beberapa di antaranya menarik, beberapa proses sepele dan mungkin yang lain-lain tidak disukai. Kejadian tersebut merupakan "sense of life" didalam sebuah permukiman, dengan serasi merupakan dasar persepsi langsung untuk pengertian-pengertian yang lebih dalam (Lynch, 1981. P: 138).

Schultz menjelaskan tentang analisis struktur dan sifat dari struktur Kota Praha dan sifat Kota Praha membuka perwujudan-perwujudan yang mendasar dari Genius Locinya yang sangat kuat. Transparensi dapat dianalisa melalui observasi lapangan dengan meminta para pendatang dan masyarakat setempat, untuk menggambarkan proses-proses yang jelas sewaktu mereka memandang kearah kota, dengan jalan mendengarkan, meraba dan membaunya.

\section{Legibilitas}

Lingkungan perkotaan merupakan sarana komunikasi, yang memperagakan symbol-simbol yang tersurat maupun tersirat. Tanda-tanda ini memberikan informasi kepada kita tentang kepemilikan, status, kelompok kumpulan, fungsi-fungsi yang tersembunyi, barang-barang dan jasa, perilaku yang layak, dan banyak hal lain yang kita anggap berguna atau menarik untuk diketahui. Sistem simbol atau tanda-tanda lingkungan tersebut, hampir seluruhnya merupakan suatu kreasi sosial, dan seringkali tidak dikenali asal budayanya.

Kondisi tersebut dapat dianalisa melalui konteks kebenaran, intensitas oleh para pengamat yang mengenal. Dari penemuan-penemuan tersebut bisa dipertegas dengan wawancara dan tes-tes simulasi fotografis yang dilakukan dengan para penduduk setempat, sehingga dapat diperoleh arti sesungguhnya dari tempat tersebut, baik pada tempat yang sempurna, sepele, cocok atau tidak cocok, penting atau remeh, terbuka atau dominasi. Hal-hal ini mengakar pada tempat atau waktu bersama dengan aktivitas-aktivitas, orang-orang, atau kondisi dari kotanya. Pencapaiannya mungkin bisa melalui bentuk lingkungan yang diciptakan; lingkungan yang dikombinasikan dengan cara baru dan lain-lain. Dari kondisi yang demikian akan mengakibatkan pengembangan tentang bahasa ruang, dalam arti luas dapat membangkitkan kemampuankemampuan penduduk kota untuk berkomunikasi dengan ruang.

\section{METODE PENELITIAN}


Penelitian ini menggunakan observasi dalam metode pengumpulan data kasus. Dalam pelaksanaannya dapat dibagi menjadi dua bagian yaitu observasi kondisi fisik dan observasi kondisi non fisik (manusia). Observasi kondisi fisik, yaitu berupa pengamatan yang mendalam tentang gambaran situasi dan kondisi secara umum, kecenderungan trend fisik, ciri fisik/style yang bisa bertahan lama dan kejelasan orientasi fisik secara struktural. Observasi kondisi non fisik (manusia), yaitu berupa pengamatan yang mendalam tentang aliran kecenderungan kegiatan dan kesesuaian antara aktivitas dan fasilitas. Observasi dilakukan dalam aspek-aspek kriteria kinerja Teori Perancangan Kota Kevin Lynch. Modifikasi dilakukan untuk mempermudah penerapan pada kasus studi sebagai berikut :

\section{Identitas}

A Sense of Place merupakan pengenalan bentuk ruang dan kualitas, ini bila tercapai dengan baik akan menimbulkan keunikan tersendiri bila dibandingkan dengan bentuk dan kualitas ditempat lain. Bentuk dan kualitas ini digambarkan oleh Schulz berupa kondisi jalan, jembatan, halaman bangunan, tangga/pintu pagar rumah, hubungan pengamat dengan elemenelem fisik di ketinggian (puncak bangunan, puncah menara, tiang, dsb). Sense of Occasion merupakan fungsi dan makna dari suatu objek, dengan tujuan menggabungkan bentuk dan aktivitas agar tersirat sebagai place. Sedang place itu sendiri sudah mengkaitkan arti kontekstual dari kandungan budaya masyarakatnya, dengan begitu timbul tipologi yang unik, khas dan dapat memberikan karakter khusus terhadap lingkungan tersebut.

Struktur
Hubungan skala dari tempat yang terkecil dengan bagian-bagian tempat lain dalam suatu orientasi yang baik, dapat mempunyai arti tersendiri. Mencapainya dapat dibantu dari: nodes, paths, edges, landmark dan distrik. Sedang penggambaran pada pusat kota dapat berupa Gerbang (gateway), Jalan (paths), Ruang luar (open space), Bangunan (Building), Skyline, Pedestrian, Trotoar, Taman, Landmark.

\section{Congruence}

Identitas dan struktur adalah aspek-aspek bentuk yang memudahkan kita mengenal dan mempola tempat dan waktu, di dalam unsur lokasi / tempat itu sendiri. Congruence merupakan tingkatan pertama kesesuaian formal dari struktur dan Identitas, pendekatannya dengan jalan pengamatan pada aspek kesesuaian tipologi fisik sesuai dengan aktivitas masyarakat pemakainya, aktifitas tinggi pada fasilitasfasilitas yang ada, dan aktivitas yang tinggi pada pusat kota.

\section{Transparansi}

Transparensi Bila salah satu atau secara keseluruhan pendekatan dari congruence tercapai, maka timbullah pandangan hidup atau "Sense of Life" (dalam Genius Loci disebut "Jiwa") dari suatu tempat, pendekatannya bisa dari ciri-ciri fisik ataupun non fisik. Legibilitas Bisa dicapai melalui simbol-simbol yang dihasilkan dari penggabungan congruence dan transparensi, yang melahirkan bentuk-bentuk yang berupa tipologi wujud fisik bangunan, serta ciri dan bentuk kegiatan

Secara Skematis dapat digambarkan sebagai berikut: 


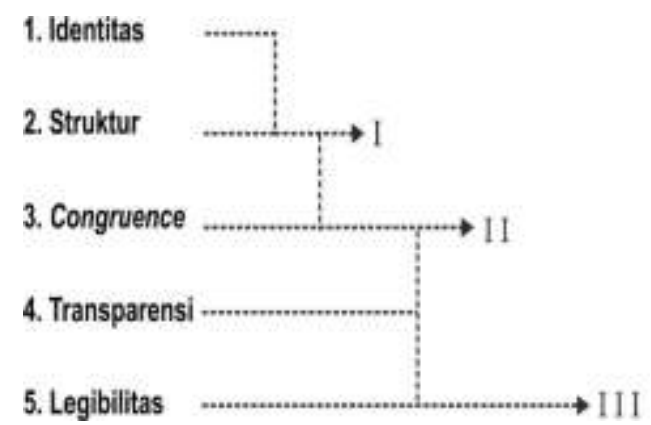

Gambar 1. Skema Analisis

\section{Keterangan}

I. Penggabungan identitas dan struktur sebagai landasan pengamatan kasus studi dapat diringkas sebagai berikut :

1. Ruang Terbuka (Open Space)

2. Jalan (Sistem Sirkulasi)

3. Bangunan (Building)

4. Bangunan Signifikan

5. Pengaturan dan Karakter visual

6. Aktivitas Pengguna

7. Fasilitas Pendukung

II. Penggabungan identitas, struktur, dan congruence, dapat berupa pengamatan yang cermat terhadap kesesuaian antara: (1) tipologi fisik dengan aktivitasnya dan (2) ciri-ciri aktivitas yang terbentuk dengan pendekatan fisik dan non fisik

III. Penggabungan congruence, transparensi dan legibilitas diharapkan dapat menilai bentuk-bentuk: (1) tipologi fisik serta ciri dan (2) bentuk kegiatan
Dari rangkuman diatas dapat disimpulkan sebagai unsur-unsur yang akan diamati pada kasus studi di pusat kota Malang, adalah :

1. Ruang Luar (open space)

2. Bangunan (building)

3. Bangunan signifikan

4. Sistem sirkulasi

5. Pengaturan dan karakter visual

6. Aktivitas pengguna

7. Fasilitas Pendukung

Sedang analisis visual dan non visual dari :

8. Tipologi fisik dan aktivitas, serta

9. Ciri-ciri aktivitas yang terbentuk

\section{Hasil dan Pembahasan}

Kawasan Pusat Kota Malang memiliki karakter fisik yang cukup dikenal, baik secara tipologi maupun struktur dalam bentuk serial vision. Pengamatan aktivitas yang terjadi dapat diuraikan sebagai berikut :

Tabel 2. Analisis Identitas dan Karakter Kawasan

Kayutangan

\section{Kawasan Kayutangan}




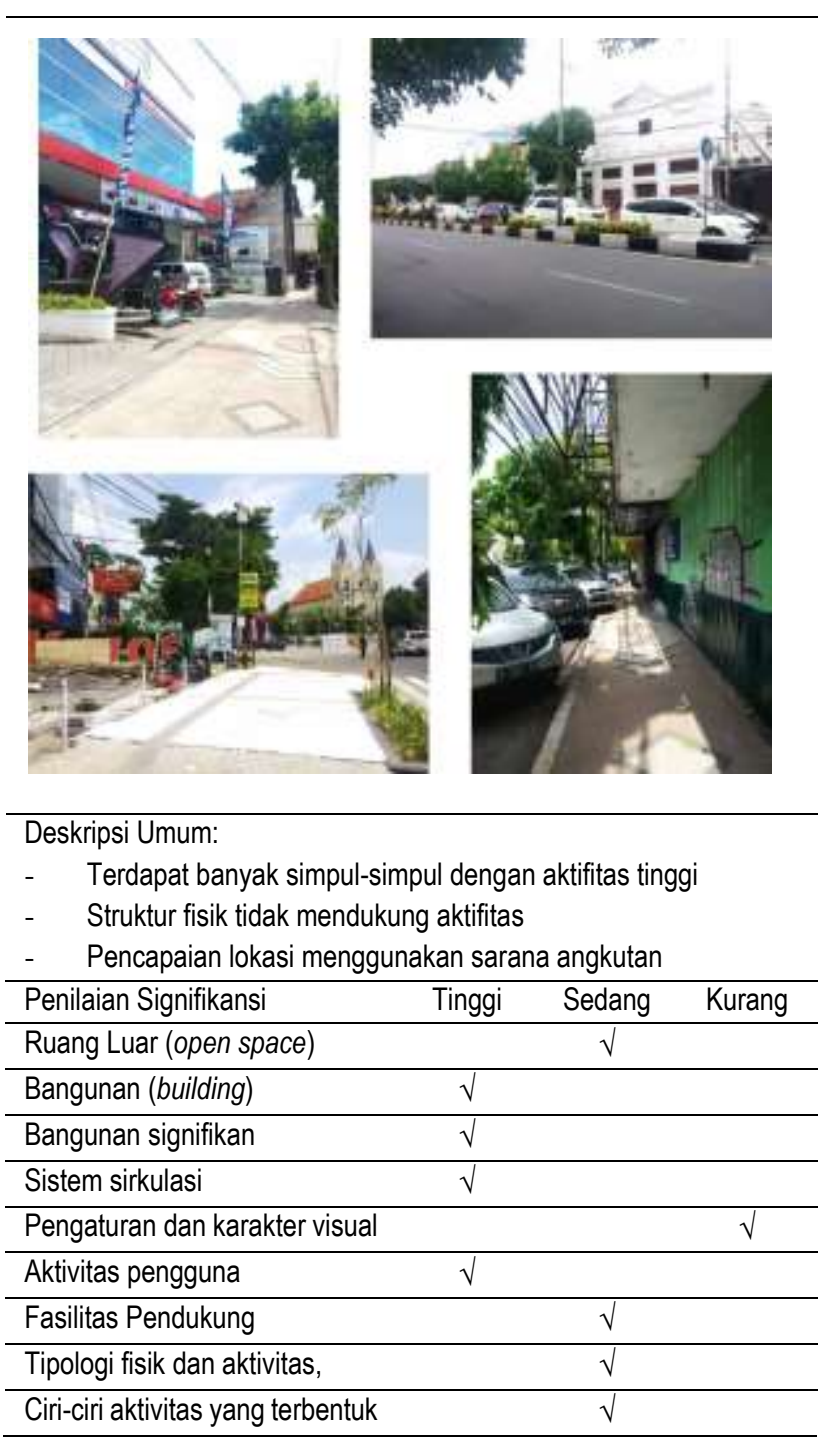

Tabel 3. Analisis Identitas dan Karakter Kawasan Alun-alun

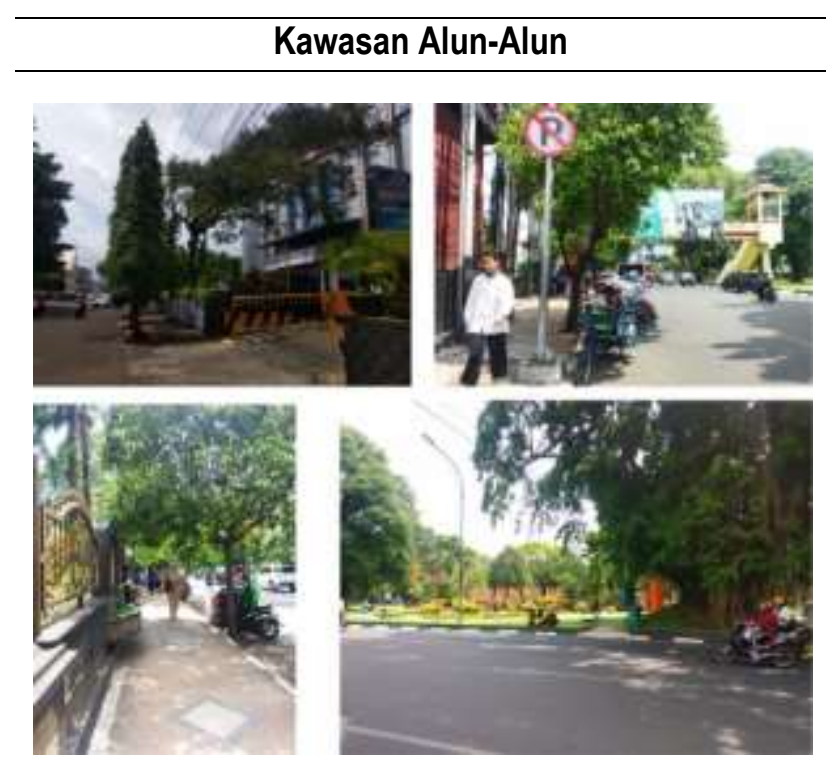

\section{Deskripsi Umum:}

- $\quad$ Terdapat banyak simpul-simpul dengan aktifitas tinggi

- $\quad$ Struktur fisik kurang mendukung aktifitas

- Pencapaian lokasi menggunakan sarana angkutan

\begin{tabular}{lccc}
\hline Penilaian Signifikansi & Tinggi & Sedang & Kurang \\
\hline Ruang Luar (open space) & $\sqrt{ }$ & & \\
\hline Bangunan (building) & & $\sqrt{ }$ & \\
\hline Bangunan signifikan & $\sqrt{ }$ & & \\
\hline Sistem sirkulasi & & $\checkmark$ & \\
\hline Pengaturan dan karakter visual & & & $\checkmark$ \\
\hline Aktivitas pengguna & $\checkmark$ & & \\
\hline Fasilitas Pendukung & & & $\checkmark$ \\
\hline Tipologi fisik dan aktivitas, & $\sqrt{ }$ & & \\
\hline Ciri-ciri aktivitas yang terbentuk & $\sqrt{ }$ &
\end{tabular}

Tabel 4. Analisis Identitas dan Karakter Kawasan Agus Salim 


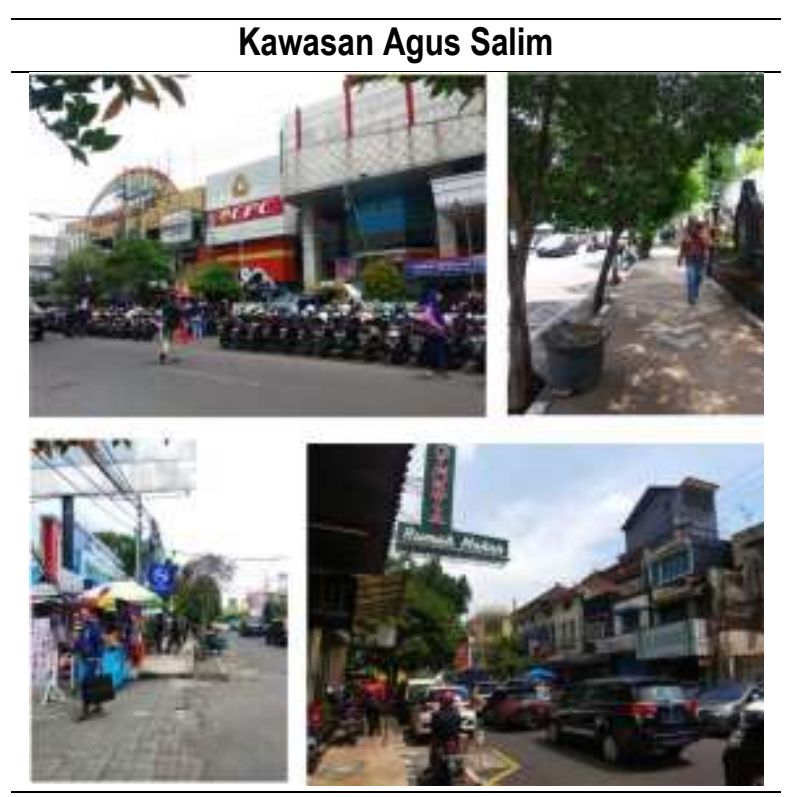

Deskripsi Umum:

- $\quad$ Terdapat banyak simpul-simpul dengan aktifitas tinggi

- $\quad$ Struktur fisik mendukung aktifitas

- $\quad$ Pencapaian lokasi menggunakan sarana angkutan

\begin{tabular}{|c|c|c|c|}
\hline Signifikansi & Tinggi & Sedang & Kurang \\
\hline Ruang Luar (open space) & & & $\sqrt{ }$ \\
\hline Bangunan (building) & $\sqrt{ }$ & & \\
\hline Bangunan signifikan & & $\sqrt{ }$ & \\
\hline Sistem sirkulasi & $\sqrt{ }$ & & \\
\hline $\begin{array}{l}\text { Pengaturan dan karakter } \\
\text { visual }\end{array}$ & & $\sqrt{ }$ & \\
\hline Aktivitas pengguna & $\sqrt{ }$ & & \\
\hline Fasilitas Pendukung & & & $\sqrt{ }$ \\
\hline Tipologi fisik dan aktivitas, & $\sqrt{ }$ & & \\
\hline $\begin{array}{lll}\text { Ciri-ciri aktivitas yang } \\
\text { terbentuk }\end{array}$ & $\sqrt{ }$ & & \\
\hline
\end{tabular}

\section{Respon pengenalan masyarakat}

Hasil analisis menunjukkan pengenalan ("sense") masyarakat terhadap bentukan lingkungan fisik, bentuk dan karakter pusat Kota Malang dengan bentuk "tipologi" bangunannya cukup baik. Pengenalan “struktur" fisik khususnya bentuk bangunan signifikan kurang dipahami fungsi dan maknanya, sehingga menyebabkan "kekaburan" identitas. Hal ini disebabkan adanya ketidaksesuaian aktivitas, karena terjadi alih-ubah fungsi Yang sering mengaburkan makna bangunan tersebut, bahkan menjadi "asing" bagi masyarakat. Bentuk fisik bangunan yang "spesifik" dan secara visual dominasi baik dari segi orientasi maupun peran penampilannya kurang mendapat kesan.

Yang terjadi bahkan respon positif (pengenalan) lebih pada bentuk arsitektural (building) yang kurang menonjol/ dominasi tetapi dengan intensitas kegiatan yang tinggi. Dengan demikian karakter visual pusat kota (Malang) tidak hanya terbentuk dari bentukan fisik (struktur fisik tata ruang pusat kota) sebagai “wadah", tetapi tidak terlepas dari aktivitas kota (aspek nonfisik) sebagai "isi" nya. Pemaknaan karakter visual tidak terlepas dari pemahaman akan "wadah" dan “isi".

Karakter spesifik pusat kota yang telah meng "identitas" baik wujud fisik maupun non fisik, tidak terlepas dari adanya “kesepakatan" (sense) masyarakat akan objek, sehingga seseorang merasakan berada pada suatu “tempat" sebagai "place" merupakan cara yang representatif dalam menganalisa bentuk dari karakter visual pusat kota 


\section{KESIMPULAN DAN REKOMENDASI}

- Kawasan kayutangan perlu memperhatikan bagaimana agar karakter dan pandangan masyarakatnya melahirkan "Sense of Place". Struktur fisik Kayutangan yang kurang memperhatikan masalah iklim dan perlu pemecahannya seperti “arcade”, sehingga aktivitas yang terjadi dapat maksimal.

- Kawasan Alun-alun tidak ada masalah yang mendasar, hanya perlu mengoptimalkan aktivitas pada waktu-waktu iklim kurang bersahabat, dengan jalan menambah pohon-pohon pelindung dan lainlain. Sedang parkir timur Alun -alun sebaiknya dialihkan pada daerah lain agar secara jangka panjang tidak menimbulkan "crowded".

- Kawasan Agus Salim yang sudah membentuk "specific culture" pembenahannya, dengan jalan memberikan sarana pedestrian diantara pusat-pusat perdagangan, dengan harapan kekacauan yang ada beralih menjadi "specific culture" keteraturan.

- Sedang secara umum perlu acuan peraturan yang dapat mengarahkan dan membatasi setiap kegiatan pembangunan. Melalui pandangan masyarakat masyarakat diharapkan bentukan yang ada menunjang aktivitas secara khusus, tersendiri.

- Dengan demikian “matra kinerja sense" dapat dipakai sebagai acuan mengobservasi suatu bentuk kota sehingga "Sense of Place" nya bisa tergali dengan atau tanpa meninggalkan pandangan masyarakatnya.

\section{REFERENSI}

Djunaedi, Achmad. 1989. Pengantar Metodologi Penelitian Arsitektur, Jur. Teknik Arsitektur, Fakultas Teknik, Universitas Gadjah Mada, Jogjakarta.

Donald, Appleyard at al. 1960. View From The Road, Cambridge, The Technology Press and Harvard University Press.

Fu-Tuan, Y. 1977. Space and Place (The Perspective of Experience). Edward Arnold, London.

Huston, S. dan Babiano I.M. 2013. Vertical Mixed-Use Communities : A Solution to Urban Sustainability? Review Audit and Developer Perspective. Conference: 20th Annual European Real Estate Society Conference. Vienna, Austria.

Kotharkar, R., Pankaj, B., and Neha S. 2014. Measuring Compact Urban Form : A Case of Nagpur City, India. ISSN 2071-1050.

Lang, J. 1974. Designing For Human Behaviour, Stroudsborg, Pennsylvania, Downden Hutchinsonc Ross Ins.

Liaqat, H., Waheed A., et al. 2015. Measuring Urban Sustainability through Compact City Approach : A Case Study og Lahore. Journal of Sustainable Development Studies. Vol 10, No 2.

Lynch K. 1981. A Theory of Good City Form. The Massachusetts Institute of Technology, USA, p 31.

Lynch, K. 1980. A Theory of Good City Form, Cambridge The M.I.T. Press.

Mahriyar, M.Z. dan Rho, J.H. 2014. Compact City Concept in Creating Resilient City and Transportation System in Surabaya. Procedia Social and Behavioral Sciences, Volume 135, 41-49. 
Matsumoto, T. 2012. Compact City Policies: A Comparative Assessment. ppt.

Nas, P.J.M. 1986. The Indonesian City (Studies in Urban Development and Planning), DordrechtHoll and/Cinnaminson-U.S.A, Foris Publications.

Rapoport, Amos. 1977. Human Aspects of Urban Form, Sydney, Pergamon Press.

Relph E. 1976. Place and Placelessness, London, Pion Limited,

Rossi A. 1982. Architecture OfThe City, Cambridge, Mass; Massachusetts Institut of Technology Press, USA.

Schulz, C.N. 1980. Genius Loci (Towards Phenomenology of Architecture). London, A.E. p : 82.

Shirvani, H. 1985. The Urban Design Process, New York, Van Nostrand Reinhold Company.

Trancik, R. 1986. Finding Lost Space, Theories Of Urban Design. New York, Van Nostrand Reinhold Company, p.98.

Whyte, W. 1980. The Social Life of Small Urban Spaces. Washington, D.C. The Conservation Foundation.

Zeisel, J. 1981. Inquiri By Design, California, Harvard University. 